\title{
Critical Features in the Microstructural Analysis of AISI 316L Produced By Metal Additive Manufacturing
}

\author{
Abdollah Saboori ${ }^{1} \cdot$ Mostafa Toushekhah $^{1} \cdot$ Alberta Aversa $^{1} \cdot$ Manuel Lai $^{2} \cdot$ Mariangela Lombardi $^{1} \cdot$ Sara Biamino $^{1}$. \\ Paolo Fino ${ }^{1}$
}

Received: 8 August 2019 / Revised: 2 December 2019 / Accepted: 17 December 2019 / Published online: 2 January 2020

(C) The Author(s) 2019

\begin{abstract}
Directed energy deposition (DED) process is recognized as an alternative technology to produce the complex-shape AISI 316L components. The critical production step in this technology is the optimization of process parameters that can directly affect the final properties of the components. To optimize the process parameters, the residual defects of specimens produced with different combinations of process parameters are evaluated, and the optimum condition is chosen. Therefore, the residual defects assessment is a vital step in finding the optimum process parameters; therefore, this evaluation should be carried out carefully. One of the main issues in the production of AISI 316L by DED process is oxidation during the process that should be considered besides the other defects such as porosity and cracks. However, the identification between the oxides and porosities is not an easy task, and so this study aims to provide more clear insight into the evaluation of pores and oxides in DED 316L samples. The outcomes of this work show that at the best process parameters suitable for a porosity-free sample, there are some oxides that can be misinterpreted as porosity and consequently deteriorate the mechanical properties of the dense sample.
\end{abstract}

Keywords Metal additive manufacturing · Directed energy deposition · AISI 316L stainless steel · Process parameters · Defects · Oxide

\section{Introduction}

Metal additive manufacturing (AM) is a production technology to build 3D complex-shape components layer by layer by using a computer-aided design (CAD) file [1, 2]. This process allows producing precise geometric shapes in the bottom-up method [3]. In recent years, there has been an increasing interest in AM technology to be used in different industries, such as automotive, aerospace and medicine [4, 5]. The motivation for this interest is because of the flexibility in design and rapid productivity of metal AM technologies in the building of the complex and high-value parts in a single step [6]. There are two main types of AM techniques: powder bed systems and powder/wire feed systems [7, 8].

Abdollah Saboori

abdollah.saboori@polito.it; saboori1985@yahoo.com

1 Department of Applied Science and Technology, Politecnico Di Torino, Corso Duca Degli Abruzzi 24, 10129 Turin, Italy

2 IRIS S.r.l., Corso Unione Sovietica 612/21, Turin, Italy
The main difference between these two AM typologies is related to the way of material feeding: in powder bed systems, there is a layer of powder that is selectively melted, whereas in powder/wire feed processes, as directed energy deposition (DED), the powder or wire is injected into the melt pool [9].

In particular, in the DED process, powder is directly fed into the melt pool, which is already generated using a laser beam on the surface of a metallic substrate or previously deposited layer. The energy provided by the laser beam allows melting the powder, which is delivered into the melt pool and deposited on the surface [10]. DED can be used to produce or repair the complex and high-value components [11].

In addition, the configuration of the deposition head that can be single or multinozzle or coaxial facilitates the production of the functionally graded and monolithic components as well as in situ alloying. Therefore, through this flexibility, it would be possible to design the desired microstructures and chemical compositions for various applications. 
It is reported that to produce a fully dense part, the process parameters such as laser power, scanning speed, laser focus, hatch spacing, z-step parameter, powder feeding rate and protective atmosphere have important roles, and thus they should be optimized carefully [12]. In fact, defects such as residual porosity, cracks and oxides are intrinsic to the process and have a significant influence on the thermophysical and mechanical properties of the components as well as their corrosion resistance $[13,14]$.

The last two decades have seen a growing trend towards the application of austenitic stainless steels in various applications such as petrochemical, automotive, power generation industries and biomaterial components $[15,16]$. This increasing trend is as a consequence of their excellent intergranular corrosion resistance. The traditional technologies such as welding, casting and plastic deformation like extrusion and forging are used to fabricate stainless steel components, but they are not able to produce the components with high levels of complexity [17]. Among the new developments, the DED process shows a great potential to be used as a reliable solution for the production of complex near-net-shape parts with a lower amount of material. A considerable number of previous works have been focused on the production of AISI 316L using DED process. A large number of these works focus in particular on the effect of process parameters on the mechanical properties, corrosion and microstructure of DED materials [12, 18].

Nevertheless, the effect of oxidation during the process and, consequently, oxides formation, which is found to be deleterious for the final properties of steel components, are rarely considered and investigated. Apart from the effects of oxide on the final properties, their quantification and chemical composition analysis are not well established and reported. This lack of investigation is because of the difficulty in distinguishing the porosities and oxides in the standard metallography methods. Therefore, this paper attempts to provide a methodology for analysing the microstructure of AISI 316L, considering the right porosity and oxide identification.

\section{Experimental Procedure and Results}

Gas-atomized stainless steel $316 \mathrm{~L}$ powder in the range of $50-150 \mu \mathrm{m}$ is used as a starting material. The chemical composition of the AISI 316L virgin powder is reported in Table 1.

Figure 1 shows the morphology of as-received AISI $316 \mathrm{~L}$ powder. As can be seen, the starting powder consists of mostly spherical particles, few irregular and elongated particles and small satellites. In addition to all the aforementioned characteristics, some signs of oxidation (red arrows in
Fig. 1) are revealed on the surface of starting particles that can affect the final microstructure.

Indeed, these locally oxidized areas (red arrows in Fig. 1) can be found during the atomization process, and according to previous works, they are mainly rich in $\mathrm{Si}$ and $\mathrm{Mn}$ [9]. Moreover, it is found that the presence of these oxides in the surface of particles can play a negative role on the oxide formation during the DED process.

The DED process was carried out with an IRB 4600 machine from $\mathrm{ABB} A B$ Robotics with $5 \mathrm{~kW}$ fibre laser equipped with a four-way nozzle which anticipates the laser. Argon with $99.99 \%$ purity and $51 / \mathrm{min}$ flow rate was employed as a carrier and shielding gas for metal powder particles feeding and melt pool protection, respectively. $0-90^{\circ}$ rotation per layer is selected as the scanning strategy.

Austenitic stainless steel plates with $100 \times 100 \times 10 \mathrm{~mm}$ size were employed as a substrate material for deposition. In order to remove the pollutions during the deposition, every plate was cleaned and degreased with acetone before the process. The optimization of process parameters was performed according to the procedure reported in the previous work [12]. Thereafter, the standard instruction for metallography of steel alloys was used to evaluate their microstructure and residual defects in their building direction. The microstructure and oxide content of $316 \mathrm{~L}$ alloy are evaluated at least in three samples. This method includes grinding by 500, 800, 1200, 2500 grit paper followed by polishing down to $3 \mu \mathrm{m}$ and $1 \mu \mathrm{m}$ diamond abrasives. Then, polished surfaces were etched with a solution of $15 \mathrm{~mL} \mathrm{HCl}+10 \mathrm{~mL} \mathrm{HNO}_{3}+1 \mathrm{~mL}$ acetic acid. Etchant has been applied by immersion for $9 \mathrm{~s}$. Microstructural observations were carried out on etched cross sections using the optical microscope LEICA DMI $5000 \mathrm{M}$ and scanning electron microscope (SEM) Phenom XL with energy-dispersive X-ray spectroscopy (EDS) detector. The oxygen content of starting powder and cubes

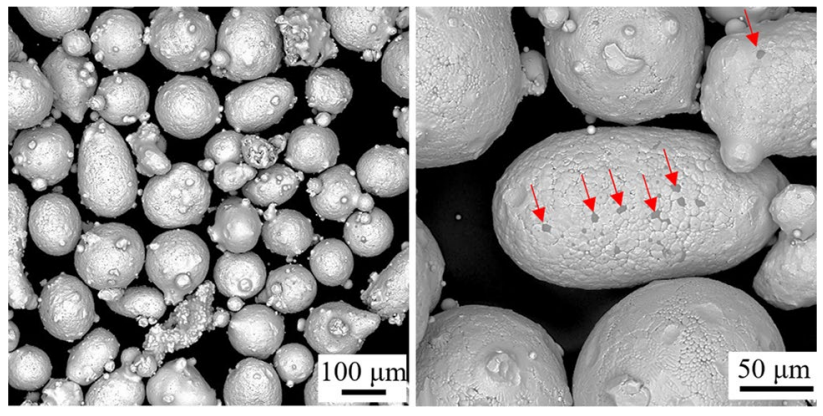

Fig. 1 SEM micrograph of the virgin AISI 316L powder
Table 1 Chemical composition of AISI 316L stainless steel powder

\begin{tabular}{llllllllll}
\hline Composition & $\mathrm{C}$ & $\mathrm{Si}$ & $\mathrm{Mn}$ & $\mathrm{Cr}$ & $\mathrm{Mo}$ & $\mathrm{Ni}$ & $\mathrm{Nb}$ & $\mathrm{Ti}$ & $\mathrm{Fe}$ \\
\hline Wt.\% & 0.02 & 0.5 & 1.8 & 16.7 & 2.0 & 10 & 0.02 & 0.05 & $\mathrm{Bal}$. \\
\hline
\end{tabular}


after the deposition was analysed using the inert gas fusion method by a LECO ONH836 Oxygen/Nitrogen/Hydrogen elemental analyser. The tensile tests were performed on DED samples built perpendicular to the building direction using a Zwick Z100 testing system using $8 \times 10^{-3} \mathrm{~s}^{-1}$ as strain rate.

Figure 2 compares the optical microscopy microstructures of AISI 316L samples produced by DED using notoptimized and optimized process parameters. In the first evaluations, both of them seem porous, and image analysis evaluation reports $3.6 \%$ and $1.3 \%$ porosity content for the samples with not-optimized and optimized process parameters, respectively. The first observations imply that even in the specimen with optimized parameters, still some spherical gas-induced porosities are present (Fig. 2b). However, after a careful analysis of those samples by SEM, surprisingly, it is found that the black areas in the microstructure are not porosity. As a matter of fact, different types of porosities can be detected after DED process. Spherical pores are generally referred as gas-induced porosities and appear during the interaction between the powder particles and the molten phase. Ejections as the vaporized metal from the melt pool or metallic vapours blowing away non-melted particles were found as potential causes of gas-induced porosity during the manufacturing of components. However, irregular pores that generally referred as process-induced porosity are formed due to the irregular flow in the melt pool or lake of fusion as a consequence of not sufficient heat input. The EDS maps reveal that the black areas are either enriched in oxygen and silicon or enriched in oxygen, silicon and manganese (Fig. 3). The presence of these oxides in the microstructure can cause a misinterpretation in the optimization of process parameters and consequently influence the optimization process adversely.

As can be seen in Fig. 3, the black areas in the OM micrographs are inclusions rich in oxygen, silicon and manganese. In addition, according to the EDS maps, it is possible to underline that there are two kinds of oxides: the small oxides (almost $500 \mathrm{~nm}$ ) are rich in silicon, whereas the larger ones (almost $5 \mu \mathrm{m}$ ) are rich in silicon and manganese. The formation of these oxides in the AISI 316L samples produced by DED can be possibly related to several issues, such as the high oxygen content of the starting powder, the high oxygen content in the deposition chamber and not wellregulated shielding gas flow rate. Oxygen content analysis of cubic specimens after DED reveals that their oxygen content is around $1600 \pm 67 \mathrm{ppm}$, which is almost five times higher than the value of the starting powder $(350 \pm 84 \mathrm{ppm})$. However, it should be noticed that the oxygen content of

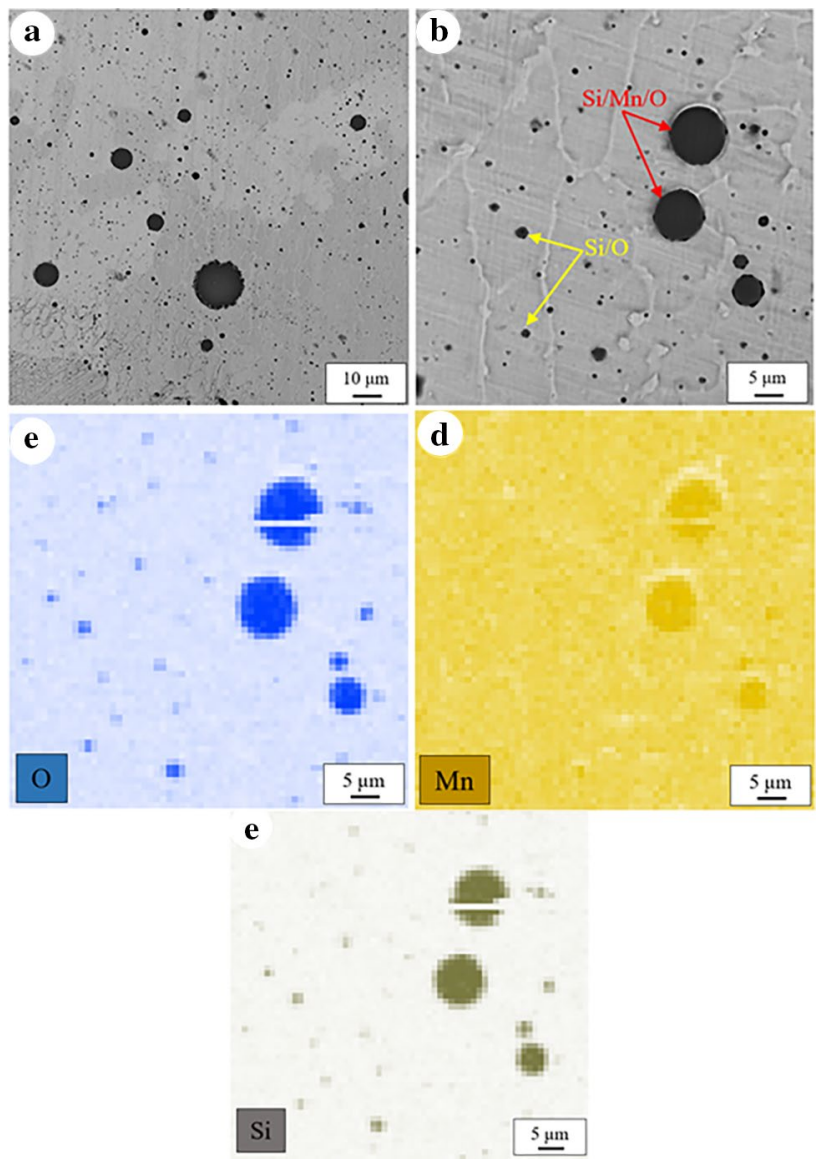

Fig. 3 (a, b) SEM micrograph, (c-e) EDS maps corresponding to O, $\mathrm{Mn}$ and $\mathrm{Si}$, respectively, of a dense sample produced by DED with the optimized process parameters
Fig. 2 OM micrograph of AISI $316 \mathrm{~L}$ produced by DED, (a) before optimizing the process parameters, (b) after optimizing the process parameters
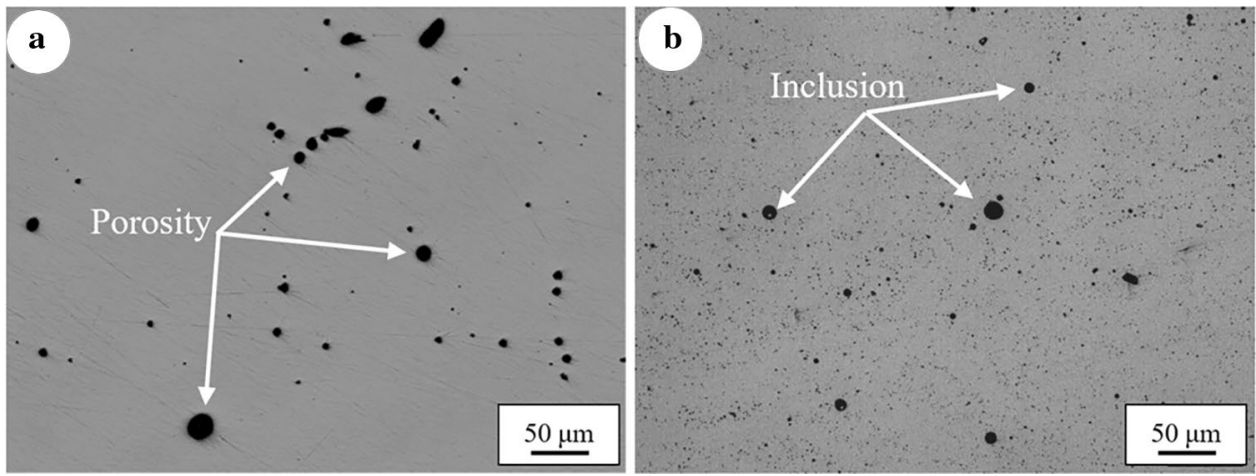
Table 2 Comparison between the mechanical characteristics of the samples produced in this work and literature

\begin{tabular}{llll}
\hline & Yield strength, MPa & $\begin{array}{l}\text { Ultimate tensile } \\
\text { strength, MPa }\end{array}$ & Elongation, \% \\
\hline DED-90 $^{\circ}$ & $468.74 \pm 5.5$ & $648.60 \pm 1.6$ & $22.57 \pm 2.6$ \\
DED-90 $^{\circ}[7]$ & $405-415$ & $620-660$ & $32-40$ \\
\hline
\end{tabular}

the powder and bulk samples is the average of three measurements. Moreover, the bulk samples were cut from the central part of each cube to have a same position for all the measurements.

Apart from the negative effect of these oxides on the optimization of process parameters, their influence on the mechanical properties of $316 \mathrm{~L}$ materials processed by DED would be detrimental. Tensile properties of the samples are reported in the Table 2.

For example, the elongation of 316L samples consists of oxides decreases down to $22.57 \pm 2.6 \%$, while the elongation of the oxide-free $316 \mathrm{~L}$ sample produced via DED is almost $40 \%$ higher [7]. During the tensile test, the oxide inclusions within the AISI 316L can behave as reinforcement and improve the mechanical strength sacrificing the elongation of the alloy [19]. However, it should be noticed that the strengthening efficiency of these inclusions was limited due to their size that this finding is in line with the literature [20, 21]. Thus, for all the reasons, a careful control of the starting powder and deposition process is necessary in order to find the best process parameters that minimize the porosity but also the formation of the oxide.

\section{Conclusion}

It was demonstrated that in the case of AISI 316L produced by DED, the quantification of both the residual porosity and oxides formation plays a key role and should be carried out carefully during the optimization of process parameters. In fact, due to several reasons such as the high oxygen content of starting powder, the high oxygen content of deposition chamber and not well-regulated shielding gas flow rate, some oxides either rich in $\mathrm{Si}$ (very fine, around $500 \mathrm{~nm}$ ) or rich in Si and Mn (coarse, about $5 \mu \mathrm{m}$ ) are formed within the samples. The formation of inclusion is found to be effective on the tensile behaviour of the dense $316 \mathrm{~L}$ samples produced by DED so that they significantly reduce their elongation, but slightly improve their ultimate tensile strength. For a correct process parameter optimization, during sample characterization, the oxides must be recognized considering them differently from the residual gas-induced porosity, thus reaching a compromise in the process parameters optimization in order to minimize both of them. All in all, it is interesting to note that to evaluate the porosity or oxide content of $316 \mathrm{~L}$ samples, not only image analysis by $\mathrm{OM}$ is not enough, but also it is necessary to analyse the microstructure of as-polished samples via either SEM and/ or micro-computed tomography.

Acknowledgements The authors would like to acknowledge the European research project belonging to the Horizon 2020 research and innovation program and 4D Hybrid-Novel ALL-IN-ONE machines, robots and systems for affordable, worldwide and lifetime distributed 3D hybrid manufacturing and repair operations (Grant Agreement No. 723795).

Conflict of interest The authors declare no conflict of interest.

Open Access This article is licensed under a Creative Commons Attribution 4.0 International License, which permits use, sharing, adaptation, distribution and reproduction in any medium or format, as long as you give appropriate credit to the original author(s) and the source, provide a link to the Creative Commons licence, and indicate if changes were made. The images or other third party material in this article are included in the article's Creative Commons licence, unless indicated otherwise in a credit line to the material. If material is not included in the article's Creative Commons licence and your intended use is not permitted by statutory regulation or exceeds the permitted use, you will need to obtain permission directly from the copyright holder. To view a copy of this licence, visit http://creativecommons.org/licenses/by/4.0/.

\section{References}

1. A. Saboori, D. Gallo, S. Biamino, P. Fino, M. Lombardi, An overview of additive manufacturing of titanium components by directed energy deposition: microstructure and mechanical properties. Appl. Sci. (2017). https://doi.org/10.3390/app7090883

2. K.S. Prakash, T. Nancharaih, V.V.S. Rao, Additive manufacturing techniques in manufacturing - an overview. Mater. Today Proc. 5, 3873-3882 (2018). https://doi.org/10.1016/j.matpr.2017.11.642

3. M. Aristizabal, P. Jamshidi, A. Saboori, S.C. Cox, M.M. Attallah, Laser powder bed fusion of a $\mathrm{Zr}$-alloy: tensile properties and biocompatibility. Mater. Lett. 259, 126897 (2020). https://doi. org/10.1016/j.matlet.2019.126897

4. J.C. Najmon, S. Raeisi, A. Tovar 2-review of additive manufacturing technologies and applications in the aerospace industry. in Additive Manufacturing for the Aerospace Industry; ed by F. Froes, R. Boyer (Elsevier, 2019), pp. 7-31. ISBN 978-0-12-814062-8.

5. L.J. Bond, L.W. Koester, H. Taheri, NDE in-process for metal parts fabricated using powder based additive manufacturing. in Smart Structures and NDE for Energy Systems and Industry 4.0, vol. 10973 (2019), p. 1097302. https://doi.org/10.1117/12.2520611

6. N. Shamsaei, A. Yadollahi, L. Bian, S.M. Thompson, An overview of direct laser deposition for additive manufacturing; Part II: mechanical behavior, process parameter optimization and control. Addit. Manuf. 8, 12-35 (2015). https://doi.org/10.1016/j.addma 2015.07.002

7. M. Ma, Z. Wang, X. Zeng, A comparison on metallurgical behaviors of $316 \mathrm{~L}$ stainless steel by selective laser melting and laser cladding deposition. Mater. Sci. Eng. A 685, 265-273 (2017). https://doi.org/10.1016/j.msea.2016.12.112

8. A. Saboori, S. Tusacciu, M. Busatto, M. Lai, S. Biamino, P. Fino, M. Lombardi, Production of single tracks of Ti-6Al-4V by directed energy deposition to determine the layer thickness for 
multilayer deposition. J. Vis. Exp. 2018, e56966 (2018). https:// doi.org/10.3791/56966

9. A. Saboori, A. Aversa, F. Bosio, E. Bassini, E. Librera, M. De Chirico, S. Biamino, D. Ugues, P. Fino, M. Lombardi, An investigation on the effect of powder recycling on the microstructure and mechanical properties of AISI 316L produced by directed energy deposition. Mater. Sci. Eng. A (2019). https://doi.org/10.1016/j. msea.2019.138360

10. F. Bosio, A. Saboori, A. Lacagnina, E. Librera, M. Chirico De, S. Biamino, P. Fino, M. Lombardi, Directed energy deposition of 316L steel: effect of type of powders and gas related parameters. in Euro PM2018 Congress \& Exhibition; Bilbao (Spain, 2018), pp. 1-6.

11. J. Yu, M. Rombouts, G. Maes, Cracking behavior and mechanical properties of austenitic stainless steel parts produced by laser metal deposition. Mater. Des. 45, 228-235 (2013). https://doi. org/10.1016/j.matdes.2012.08.078

12. A. Saboori, F. Bosio, E. Librera, M. Chirico De, S. Biamino, M. Lombardi, P. Fino, Accelerated process parameter optimization for directed energy deposition of $316 \mathrm{~L}$ stainless steel. in Euro PM2018 Congress \& Exhebition; Bilbao (Spain, 2018), pp. 1-6.

13. D. Kianersi, A. Mostafaei, A.A. Amadeh, Resistance spot welding joints of AISI 316L austenitic stainless steel sheets: Phase transformations, mechanical properties and microstructure characterizations. Mater. Des. 61, 251-263 (2014). https://doi.org/10.1016/j. matdes.2014.04.075

14. P. Guo, B. Zou, C. Huang, H. Gao, Study on microstructure, mechanical properties and machinability of efficiently additive manufactured AISI 316L stainless steel by high-power direct laser deposition. J. Mater. Process. Technol. 240, 12-22 (2017). https ://doi.org/10.1016/j.jmatprotec.2016.09.005

15. M. Dadfar, M.H. Fathi, F. Karimzadeh, M.R. Dadfar, A. Saatchi, Effect of TIG welding on corrosion behavior of 316L stainless steel. Mater. Lett. 61, 2343-2346 (2007). https://doi.org/10.1016/j. matlet.2006.09.008
16. J.W. Elmer, S.M. Allen, T.W. Eagar, Microstructural development during solidification of stainless steel alloys. Metall. Trans. A 20, 2117-2131 (1989). https://doi.org/10.1007/BF02650298

17. M.S.F. de Lima, S. Sankaré, Microstructure and mechanical behavior of laser additive manufactured AISI 316 stainless steel stringers. Mater. Des. 55, 526-532 (2014). https://doi. org/10.1016/j.matdes.2013.10.016

18. S.A. Khairallah, A.T. Anderson, A. Rubenchik, W.E. King, Laser powder-bed fusion additive manufacturing: Physics of complex melt flow and formation mechanisms of pores, spatter, and denudation zones. Acta Mater. 108, 36-45 (2016). https://doi. org/10.1016/j.actamat.2016.02.014

19. A. Saboori, S.K. Moheimani, M. Pavese, C. Badini, P. Fino, New nanocomposite materials with improved mechanical strength and tailored coefficient of thermal expansion for electro-packaging applications. Met. (Basel) 7, 536 (2017)

20. P. Ganesh, R. Giri, R. Kaul, P. Ram Sankar, P. Tiwari, A. Atulkar, R.K. Porwal, R.K. Dayal, L.M. Kukreja, Studies on pitting corrosion and sensitization in laser rapid manufactured specimens of type 316L stainless steel. Mater. Des. 39, 509-521 (2012). https ://doi.org/10.1016/j.matdes.2012.03.011

21. Q. Chao, V. Cruz, S. Thomas, N. Birbilis, P. Collins, A. Taylor, P.D. Hodgson, D. Fabijanic, On the enhanced corrosion resistance of a selective laser melted austenitic stainless steel. Scr. Mater. 141, 94-98 (2017). https://doi.org/10.1016/j.scriptamat 2017.07.037

Publisher's Note Springer Nature remains neutral with regard to jurisdictional claims in published maps and institutional affiliations. 